\title{
Report on Power Compensation and Total Harmonic Distortion Level Analysis
}

\author{
Nikita Ramesh Kalaskar, Rajesh Holmukhe \\ Department of Electrical Engineering, Bharati Vidyapeeth Deemed University College of engineering, Pune, India
}

\begin{tabular}{l}
\hline \hline Article Info \\
\hline Article history: \\
Received Apr 10, 2016 \\
Revised Oct 24, 2016 \\
Accepted Nov 7, 2016 \\
\hline
\end{tabular}

\section{Keyword:}

Active filter

Capacitor bank

Harmonic study

Passive filter

Pharmaceutical industries

\begin{abstract}
In the chart of Indian science based industry, pharmaceutical industry is on top position. So it is essential to fulfil such critical requirement or demand, production should be with high speed. For such high production, using of software based machineries, electronic circuits are been used. By using such electronic based equipment's and machineries, it is obvious day by day increasing non-linear load of the industry which lead to lagging power factor. In electric system nonlinear load with low power factor draws more current from source. So because of such high current drawn, life of switchgear, wire and other electrical equipment decreases. So due to large equipment and wasted energy, the electrical utilities company usually charge a higher cost to industrial customer for the constant logging power factor. To improving the lagging power factor, industry may prefer to install capacitor bank in series. But installation of capacitor power bank leads to the increment of total harmonics distortion level. In common plant, containing power factor correction capacitor, It is been seen that normal resonant frequency falls normally in the range of $5^{\text {th }}$ to $13^{\text {th }}$ harmonics. So this non-linear load leads to inject current at $5^{\text {th }}, 7^{\text {th }}, 11^{\text {th }}$ and $13^{\text {th }}$ harmonics. It will usually result on producing the problems with switchgears, damaged capacitor banks and failure to the electrical distribution system.
\end{abstract}

Copyright $@ 2016$ Institute of Advanced Engineering and Science. All rights reserved.

\section{Corresponding Author:}

Nikita Ramesh Kalaskar,

Mtech Electrical Engineering,

Bharati Vidyapeeth Deemed University College of engineering,

Pune, India.

Email: ikiikalaskar@gmail.com

\section{INTRODUCTION}

In Ideal condition, electricity supply should show perfect sinusoidal voltage at every customer point. However because of no. of reason consumer could not maintain desirable condition. This difference from ideal voltage and current wave form to distorted waveform, termed as waveform distortion and often known as harmonic distortion. To maintain ideal condition is responsibility of both utility and consumer. But when consumer fail to maintain such desirable condition, electricity get wasted which is not been tolerated by electricity board .The major concern of utility is to maintain quality of voltage. While industrial consumer is responsible for quality of current. Harmonics may present in plant or may enter in plant from utility. Because of this harmonics, Industries have to face many problems like malfunctioning of devices, power loss in electrical devices, deteriorating of devices/machineries, errors in measurement and many more. Many more utilities impose penalty for poor power factor on industries for correcting this condition .Because of this industries start use of capacitor bank, but this increased use may draw harmonic current to the system too. Then consumers have to proceed with another option like filter. 


\section{LITERATURE REVIEW}

In some years ago most of the electrical equipment operated on ideal wave form of current and voltage. But as we introduced electronic devices to increase our equipment performance and accuracy. Many more problems arise like noise, friction, loss of power factor, unwanted errors in measurements, malfunctioning of equipment. And thus the harmonic introduce. This is been stated by Mike Holt in his one book. He also studied types of load which causes such type of problems. Also he studied that for performing well and for giving best output, equipment needs clean power. Also stated that now a day collecting process speed increases. Hence increase in use of computers which leads to the harmonics distortion. Then he studied the past, present and future trends which leads to the use of non linear loads and hence harmonic increases in power system. Then he studied which types of load causes harmonics current and he came to know the conclusion that it's very serious issue to resolve the matter.

For better performance industries need to use of all type of static converters, but still there is problems to control the harmonics and reactive power. So IEEE 519-1992 provides the application guide, limitations of disturbances and effect on the other equipment are recommended.

Author W. Mack Grady and Robert J Gilleskie started in their paper "Harmonics and how they relate power factor" that mentioned in harmonics which occurs in power system due to nonlinear load present in the industries is related with the power factor. They started that how is the power factor in the sinusoidal conditions as well in non sinusoidal conditions. They mention the example of linear and non linear loads and conclude that harmonics and power factor are co-related with each other like life and breath. If harmonics are present in the system then no one can mentioned the unity power factor and hence the losses of active power.

\section{REASEARCH METHODOLOGY OF POWER FACTOR AND HARMONIC DISTORTION LEVEL}

Power factor load varies from $-1-0+1$. The Resistive loads like bulbs, heaters etc take current at unity power factor (i.e.1). Other loads like electric motors, computers, Inverter, UPS systems, tube lights etc take current at power factors which are less than 1 . Electrical Power=One unit of electricity=1Kilowatt $\mathrm{x} 1$ Hr. If we use $1 \mathrm{KW}$ for 1 hour then the utility meter advances by 1 unit.

It is clear from above that if power factor is low, utility company electricity board has to supply us more current while delivering same power but gets same revenue from us. Nonlinear loads like computer, VFDs, UPS, Inverter, rectifiers, Battery chargers take non sinusoidal current waveform while sinusoidal voltage waveform is applied to them.

Mathematically it is proved that these non-sinusoidal currents are made up of sinusoidal currents having frequencies which are integral multiples of fundamental frequency i.e. $50 \mathrm{~Hz}$. These $(3 \mathrm{rd}=150 \mathrm{~Hz}$, $5 \mathrm{th}=250 \mathrm{~Hz}, 7 \mathrm{th}=350 \mathrm{~Hz}$ etc) currents cause overheating of transformers, cables, switchgears etc. because of increased the losses requiring their derating for normal operation. This can further cause harmonic currents in linear loads. This causes increased losses, vibrations and overheating in electrical motors, malfunctioning of electronic controls due to generated electromagnetic noise, Unwanted erratic tripping of switchgears due to over heating/over loading etc.

In electrical distribution scheme, having presence of harmonic currents, and only capacitors can be improve the system power factor. There is a possibility of amplification of these harmonics due to resonance created by transformer inductance and these capacitors. This should be avoided by using double tuned reactors L-C filters or harmonic filters in place of capacitors. Utility / Electricity distribution companies also make it mandatory for consumer to control harmonics generated by his load as it improves their revenue potential by avoiding derating. Active Harmonic filters also another solution to suppress and maintain harmonics level. These AHF are specially designed power electronic circuits, which take anti phase current from source which is equal and opposite of nonlinear component of load current.

\section{AUTHER'S CONTRIBUTION ON ANALYSIS IN ELECTRICAL HARMONIC STUDY}

It was been started with the study and understand the installed Active Harmonic Filter (AHF) panel at M/s Lupin Ltd. Biotech Division, Pune. Then it was been checked the electricity bill before and after installed the AHF panel and study. It was found that before installed harmonic filter M/s Lupin had penalized because of excessive use of required load as compare to sanction (Maximum demand) load. Then it was been studied and understood the complete electrical distribution scheme and single line diagram of the plant. Also it was been checked the current harmonics before installed AHF panel as per IEE 5191992 standard. Then reactive power compensation was been studied and made some comments on the same. From the single line diagram, electrical distribution from transformer to main LT PCC Panel and the load distribution pattern was been studied. Then size capacitor bank was been calculated and studied and also been studied the APFC 
connections to main breaker. Then linear and non linear loads were been separated from electrical load summary for control purpose.

Ensure and check the electrical parameters recorded before and after install the harmonic filter panel by using with and without capacitors back. As well as record the electrical data by using power analyzer. Check and analysis the recorded data for possible effect of current and voltage harmonics.

Description of electrical system:-

$\mathrm{M} / \mathrm{s}$ Lupin Ltd, Biotech Division is situated at Pirangut Pune. The transformer capacity is $1500 \mathrm{KVA}-22 \mathrm{KV} / 433$ volts at main incomer which is manufactured in 2008. Contract demand is $1250 \mathrm{KVA}$. The average Kwh consumption is 172000 units. The company has installed total $450 \mathrm{KVAR}$ capacitor banks at LT Panel room and is maintaining power factor near to unity to get maximum power factor incentive. These capacitors are switched on Auto and manually mode.

\section{CONCLUSION AND REPORT OF HARMONICS}

\subsection{Before installed Harmonic Filter:}

The current harmonic distortion level with normal running load and the capacitor banks are ON is as follows. The corresponding $\mathrm{kW}$ load is varying between $875 \mathrm{KW}$ to $975 \mathrm{KW}$. The average load appears to be constant around $950 \mathrm{~kW}$.

\begin{tabular}{lllllll}
\hline \multicolumn{6}{l}{ Maximum Figures of Current Harmonic Distortion Recorded } \\
Phase & THDI & 3rd & 5th & 7th & 11th & 13th \\
\hline $\mathrm{R}$ & 7.8 & 6.8 & 5.3 & 7.8 & 0.8 & 0.6 \\
$\mathrm{Y}$ & 6.8 & 4.4 & 4.4 & 5.6 & 0.6 & 0.2 \\
$\mathrm{~B}$ & 6.6 & 5.2 & 4.3 & 5.4 & 0.7 & 0.3 \\
\hline \multicolumn{7}{l}{ Max THDI figures recorded are around $7.8 \%$}
\end{tabular}

The current harmonics as shown above are around 7.8\% (Max) with capacitor banks ON and are increasing from $4 \%$ to $7.8 \%$ after application of capacitors. These harmonics are recorded at full load. The power factor measures 0.95 with this arrangement and capacitors are contributing to amplification of current harmonics.

We came to conclusion that the current harmonics as recorded on transformer LT side are well beyond limits as prescribed by IEEE 519 -1992. So suggested to install ACTIVE HARMONIC FILTER for amplification of current harmonics and shall be record within limit (below 5\%) as prescribed by IEEE 519-1992. Also suggested that the organization can also think about installing detuned harmonic (L-C) filters with steps $\left(3^{\text {rd }}, 5^{\text {th }}\right.$ and $\left.7^{\text {th }} \%\right)$ as above, so that possibility of current harmonic amplification can be avoided in future.

\subsection{After Installed Harmonic Filter:}

Load current at running load appears to be between 1600 and 1700 Amps and is fairly balanced on all three phases. Initially capacitors were kept ON and from 2 PM to 3.30 PM capacitors were kept OFF. When capacitors were kept OFF, the average THDI is 3.3 to $4.2 \%$, while for rest of the period it is $4.8 \%$. This indicates that capacitors are contributing towards amplification of harmonics.

As expected, majority of pharma industry load being nonlinear in nature, load generated harmonics are almost negligible. Following table gives values of $\%$ current harmonic distortion and actual harmonic currents at full load.

\begin{tabular}{lllllll}
\hline \multicolumn{7}{c}{ Maximum Figures of Current Harmonic Distortion \% } \\
Recorded after Installation of AHF Panel \\
Phase & THDI & 3rd & 5th & 7th & 11th & 13th \\
\hline R & 4.6 & 2.8 & 2.3 & 3.8 & 0.7 & 0.6 \\
Y & 3.5 & 2 & 2.4 & 2.7 & 0.6 & 0.2 \\
B & 3.6 & 3.2 & 2.33 & 2.4 & 0.7 & 0.3 \\
\hline
\end{tabular}

The power factor is found unity with capacitors ON conditions (Average billing power factor is between (1 to 0.95 ) and lowers side to 0.89 with capacitors OFF. 


\section{REFERENCES}

[1] HI-Tech Electrical Systems, "Effects of Harmonic Currents",

[2] Holt, M., "Harmonics, What You Should Know", http://www.electricalcontractor.net/Need_To_Know/Harmonics.htm, 1998

[3] IEEE Std 519-1992, IEEE Recommended Practices and Requirements for Harmonic Control in Electrical Power Systems, New York, NY: IEEE.

[4] J. C. Balda, et al., "Comments on the Derating of Distribution Transformers Serving Nonlinear Loads," Proc. of the Second Int'l Conf. on Power Quality: End-Use Applications and Perspectives, Atlanta, Georgia, Sept. 28-30, 1992, paper D-23.

[5] W. Mack Grady and Robert J. Gilleskie, " http://studylib.net/doc/7951074/harmonics-and-how-they-relate-topower-factor

[6] J. Arillaga,et al,"Power System Harmonics"

[7] R.C. Dugan, D.T. Rizy, "Harmonic Considerations for Electrical Distribution Feeders"

[8] "Harmonics Made Simple" by R.Fehr, P.E

[9] "Electric Utility Power System". A text book by John Smith\& McGraw-Hill. 